\title{
TRANSANAL ENDOSCOPIC MICROSURGERY IN THE MANAGEMENT OF RECTAL CARCINOID
}

\author{
Vasil Kyosev, Georgi Kotashev, Vencislav Mutafchiyski, Krasimir Vasilev, Plamen Ivanov, \\ Grigor Grigorov, Vasilena Hristova, Dimitar Penchev \\ Clinic of Endoscopic, Endocrine Surgery and Coloproctology, Department of Surgery, \\ Military Medical Academy, Sofia, Bulgaria
}

\begin{abstract}
AIMS: Carcinoid tumors, a type of neuro-endocrine tumors (NETs), comprise a heterogeneous group of neoplasms arising from cells of the neuro-endocrine system. Rectal carcinoid tumors are relatively uncommon, representing $1,1 \%$ to $1,3 \%$ of all rectal neoplasms. Their incidence is dramatically increasing. The aim of this study was to review our department's experience and assess the efficacy of transanal endoscopic microsurgery (TEM) in the management of rectal carcinoid tumor.

METHODS: Between 2013 and 2015, four patients with rectal carcinoid underwent TEM, and their clinical data were reviewed retrospectively.

RESULTS: Two patients (50\%) were identified as high-risk patients and underwent TEM, full-thickness excision and two ones (50\%) were identified as low-risk patients and underwent TEM, submucosal resection. One patient from the high-risk group was referred to us by gastroenterologist from another hospital for complete surgery after endoscopic polypectomy with microscopically tumor positive resection margin. Tumor size was bigger in high-risk patients than in low-risk ones (14 and $20 \mathrm{~mm}$ versus 7 and $9 \mathrm{~mm}$ ). There was no lymphovascular invasion in both groups. The operation time was longer in the full-thickness excision than in the submucosal resection group (45 and 55 min versus 27 and $33 \mathrm{~min}$ ). One patient with full-thickness excision was complicated with acute urinary retention. There was neither local recurrence, nor distant metastasis in our patients during the follow-up period.
\end{abstract}

CONCLUSIONS: Our data suggest that TEM is a safe, minimally invasive approach for local excision of rectal carcinoid tumors and, generally, leads to good oncological and surgical outcomes. Furthermore, for patients with microscopically positive margins after endoscopic polypectomy, TEM can be an effective surgical option for complete residual tumor removal. Scr Sci Med. 2017;49(4):64-72

Keywords: rectal carcinoid, transanal endoscopic microsurgery, full-thickness excision, submucosal resection

Address for correspondence:

Vasil Kyosev, MD

Clinic of Endoscopic, Endocrine Surgery and Coloproctology

Department of Surgery

Military Medical Academy

3, Georgi Sofiyski Street

1606 Sofia

Bulgaria

e-mail:dr_kyosev@abv.bg

Received: September 8, 2017

Accepted: December 13, 2017

\section{INTRODUCTION}

Carcinoid tumors, a type of neuro-endocrine tumors (NETs), comprise a heterogeneous group of neoplasms arising from cells of the neuro-endocrine system. Rectal carcinoid tumors are relatively uncommon, representing $1,1 \%$ to $1,3 \%$ of all rectal neoplasms. Their incidence is dramatically increasing $(1,2)$. These tumors can show a broad range of clinical behavior, from benign and asymptomatic to disseminated and metastatic (3). Because rectal car- 
Vasil Kyosev, Georgi Kotashev, Vencislav Mutafchiyski et al.

cinoid tumors often present as small and localized tumors that rarely recur after resection. Rectal carcinoid tumors have the best prognosis among all carcinoid tumors with a five-year survival rate at $88.3 \%$ and radical resection of these tumors on the basis of conventional risk stratification may be unnecessary (4-6).

A high risk of metastasis is associated with colorectal carcinoids exhibiting lymphovascular invasion or having a size $>10 \mathrm{~mm}$ (7). One study reported metastases (including lymph node and distant metastasis) in $2 \%$ of the patients with rectal carcinoids measuring $<10 \mathrm{~mm}, 10-15 \%$ of the patients with tumors measuring $10-20 \mathrm{~mm}$, and $60-80 \%$ of the patients with tumors measuring $>20 \mathrm{~mm}$ (8). Tumor size $>11 \mathrm{~mm}$ and lymphatic invasion are independent predictors of lymph node metastasis, while tumor size $>21 \mathrm{~mm}$ and venous invasion are predictive of distant metastasis (7). These findings support a strong correlation between tumor size and tumor metastasis in patients with colorectal carcinoids.

Previously reported risk factors for distant or lymph node metastasis include tumor size, histopathological differentiation, muscular invasion, and lymphovascular invasion (7,9-12). Patients with these risk factors are consequently referred to as high-risk patients who are recommended to undergo radical excision in order to decrease the possibility of distant metastasis. In fact, Onozato et al. observed no local or distant recurrence in 40 cases of rectal carcinoids with no associated risk factors (tumor size $>1 \mathrm{~cm}$ in diameter or muscular invasion) among the rectal carcinoid cases treated by endoscopy (13). They recommended the following criteria for endoscopic treatment of rectal carcinoid tumors: diameter $\leq 10 \mathrm{~mm}$, no muscular layer invasion, and no metastases to the pararectal lymph nodes $(13,14)$. Park et al. reported similar clinical outcomes of endoscopic treatment and surgical treatment in patients with rectal carcinoids measuring $10-15 \mathrm{~mm}$ in diameter and with no associated metastasis (15).

There are several methods that can be used in the resection of rectal carcinoid tumors. Recently, the endoscopic submucosal dissection (ESD) method has been widely adopted by many centers, and its use in the resection of rectal carcinoid tumors is increasing (16). ESD is a very attractive method in terms of its high rates of en bloc and complete resection (5,17-22). On the other hand, ESD is associated with a high risk of complications, especially when the endoscopist is not well-trained.

Transanal endoscopic microsurgery (TEM) was developed by Buess et al. (23) in Germany and introduced into clinical practice in 1983. TEM procedure offers several advantages over conventional transanal excision by providing much improved visualization, exposure, and access to higher lesions in the rectum. It enables accurate determination of margins and the execution of wide, full-thickness excisions under high magnification. TEM clinical efficacy for benign adenomas and T1 low-risk cancer with subsequent low complication and acceptable recurrence rates has already been widely reported (24-27). However, there is little literature regarding TEM for rectal carcinoid tumors, and the role of TEM in the treatment of rectal carcinoid tumor has not been fully detailed.

We report our clinical experiences involving four patients with rectal carcinoid tumors treated by TEM and assess the efficacy of this technique in rectal carcinoid management.

\section{MATERIALS AND METHODS}

Between 2013 and 2015, four patients with rectal carcinoid underwent TEM in our institution. Three patients were males (75\%) and the median age was 66.3 years among all of them (range: 54 to 76 years). Fourth patient was a 62 year-old female (25\%). The most common presenting symptoms were rectal bleeding, anal pain and discomfort. Data about patients' demographics, clinical presentations, treatment modalities, recurrence, and survival were retrospectively reviewed and analyzed (Table 1).

All tumors were located within $15 \mathrm{~cm}$ from anal verge and diagnosed by colonoscopy, biopsies and histopathologic evaluation. The tumor size was defined by the largest diameter of the tumor. Preoperative patients' examinations did not show any regional lymph node enlargement on computed tomography (CT) scanning or endorectal ultrasonography (EUS). All specimens were referred to pathologists and examined microscopically for tumor size, invasion depth, and resection margin status.

TEM, submucosal resection in adequately clear margins was considered as curative treatment for 
Table 1. Patients' demographics, clinical characteristics and operative technique

\begin{tabular}{lccc}
\hline & Overall & $\begin{array}{c}\text { Tumor size }<10 \mathrm{~mm} \\
\text { low-risk }\end{array}$ & $\begin{array}{c}\text { Tumor size }>10 \mathrm{~mm} \\
\text { high-risk }\end{array}$ \\
\hline Age (median) & 65.2 & 58 & 72.1 \\
Male/Female & $3 / 1$ & $1 / 1$ & $2 / 0$ \\
Bleeding & 4 & 2 & 2 \\
Tenesmus & 3 & 1 & 2 \\
Rectal mass & 1 & 0 & 1 \\
Anal pain & 1 & 0 & 1 \\
Anal discomfort & 2 & 1 & 1 \\
TEM, full-thickness excision & 2 & 0 & 2 \\
TEM, submucosal resection & 2 & 2 & 0 \\
\hline
\end{tabular}

low-risk patients with small rectal carcinoids $(<10$ $\mathrm{mm})$. For high-risk patients with larger rectal carcinoids $(>10 \mathrm{~mm})$ or those with positive margin after polypectomy, TEM, full-thickness excision would be performed. All TEM procedures were performed with the patient under general anesthesia, lithotomy position, prone or left or right lateral position, so that the lesion was situated at the bottom of the operation field. Anal dilatation was first accomplished to facilitate insertion of the operating rectal tube in anal canal. TEM, submucosal resection was performed using mixture of glycerin and fructose, normal saline, adrenaline, and methylene blue for injection into the submucosal plane to create a visible submucosal cushion for elevation of the lesion (Fig. 1 and Fig. 2). Submucosal resection was completed using the ultra-

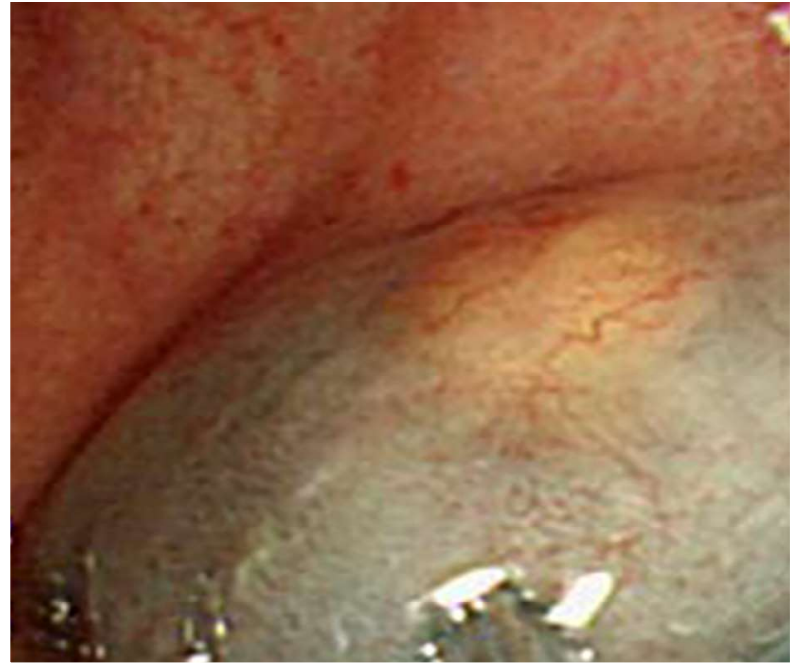

Fig. 2. Case 3. Injection into the submucosal plane

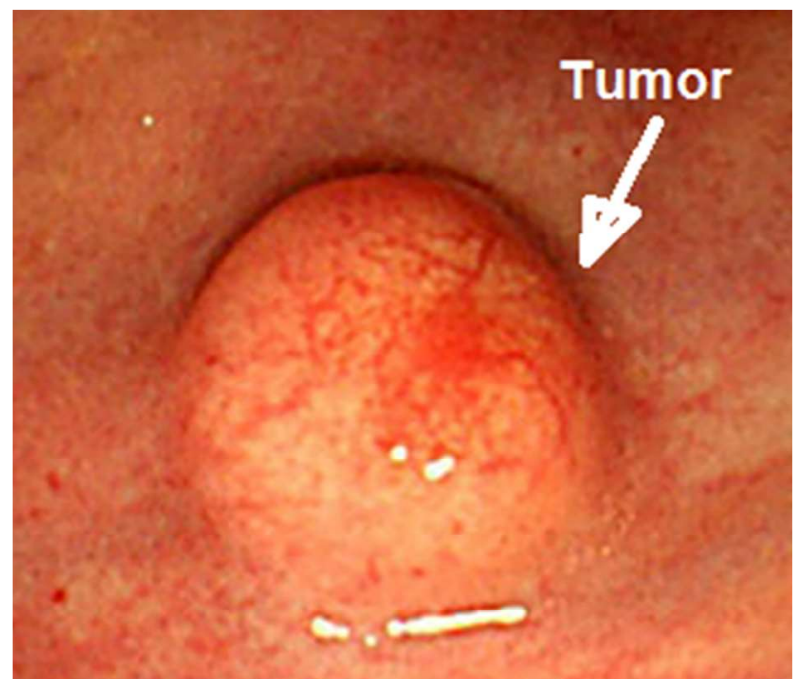

Fig. 1. Case 3. Carcinoid recti, sessile type (0-Is)

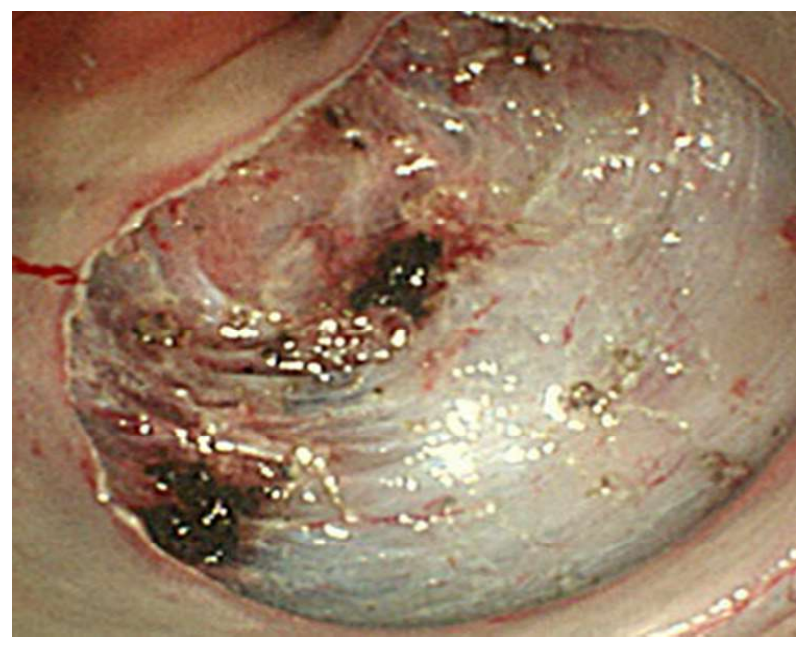

Fig. 3. Case 3. TEM, submucosal resection is completed 
Vasil Kyosev, Georgi Kotashev, Vencislav Mutafchiyski et al.

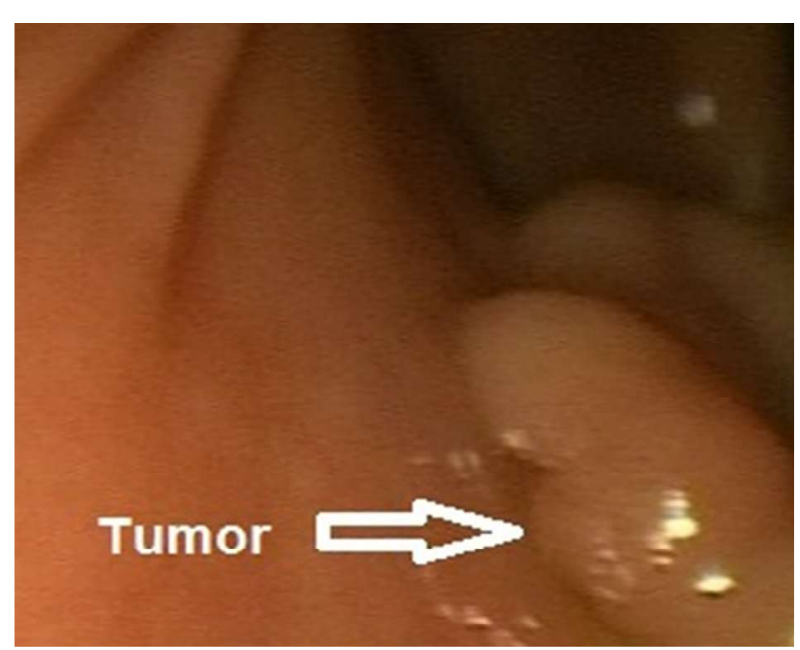

Fig. 4. Case 2. Carcinoid recti

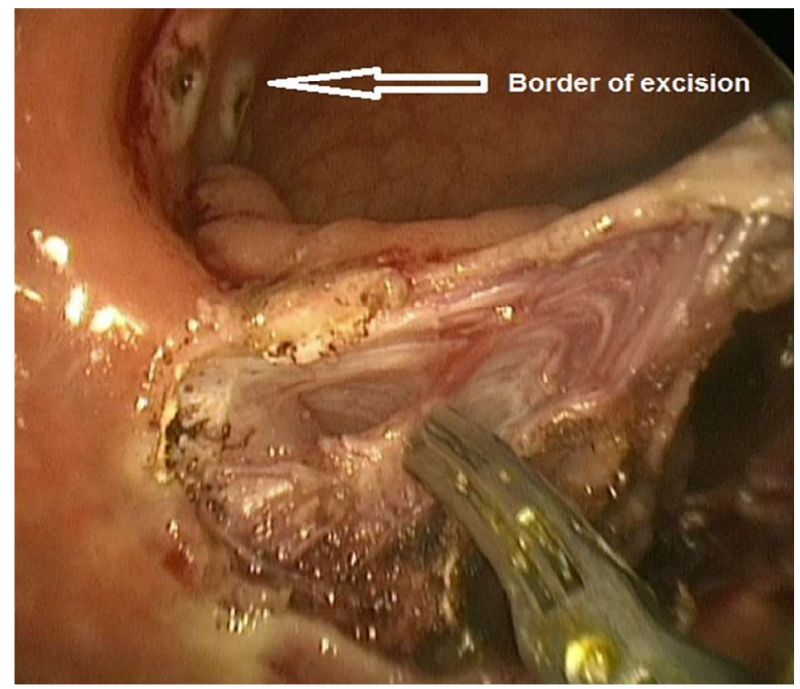

Fig. 5. Case 2. TEM, full-thickness excision

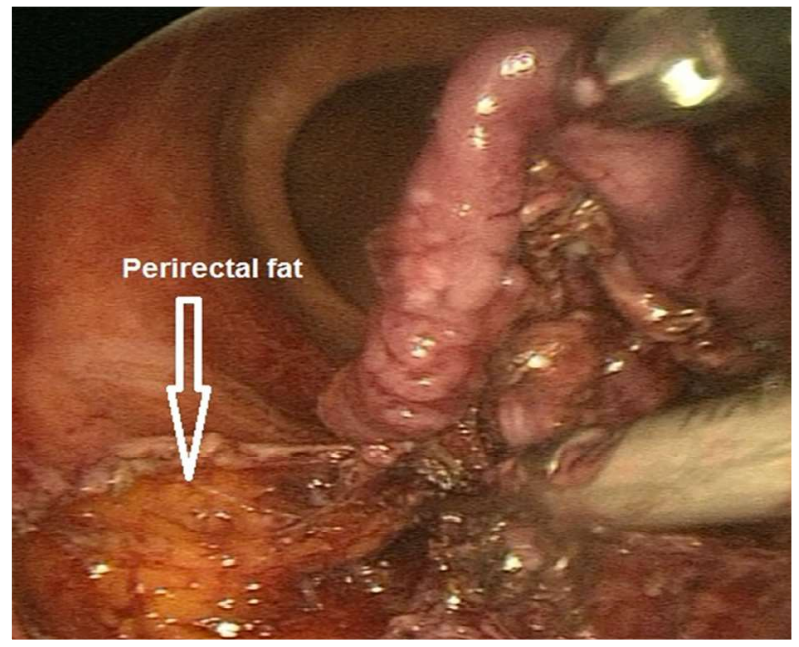

Fig. 6. Case 2. TEM, full-thickness excision

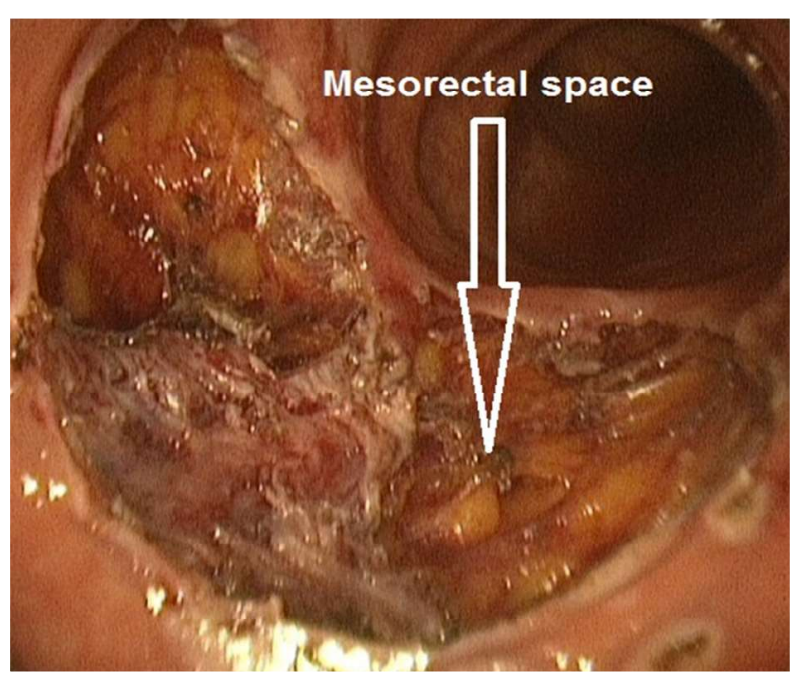

Fig. 7. Case 2. TEM, full-thickness excision is completed

Table 2. Clinicopathological and surgical characteristics of patients with rectal carcinoid treated by TEM

\begin{tabular}{lcccc} 
Case & 1 & 2 & 3 & 4 \\
Age & 54 & 69 & 62 & 76 \\
Sex & $\mathrm{M}$ & $\mathrm{M}$ & $\mathrm{F}$ & $\mathrm{M}$ \\
High/Low-risk & High-risk & High-risk & Low-risk & Low-risk \\
Location & $\mathrm{Rb}$ & $\mathrm{Ra}$ & $\mathrm{Ra}$ & $\mathrm{Rs}$ \\
Distance from the dentate line (cm) & 5 & 8 & 10 & 13 \\
Size of primary tumor (mm) & 14 & 20 & 9 & 7 \\
Depth of invasion & Submucosa & Muscularis propria & Submucosa & Mucosa \\
Lymphatic invasion & Absent & Absent & Absent & Absent \\
Vascular invasion & Absent & Absent & Absent & Absent \\
Operation time (min) & 45 & 55 & 27 & 33 \\
Resection & R0 & R0 & R0 & R0 \\
Follow-up (months) & 34 & 22 & 29 & 46 \\
\hline
\end{tabular}


sonic scissors, then the wound was closed with absorbable sutures (Fig. 3).

Before TEM, full-thickness excision the scheduled resection area, including the tumor and a clearance margin of $1 \mathrm{~cm}$, was circled with coagulation dots by a needle electrode, and resection was completed using the ultrasonic scissors (Fig. 4, Fig. 5, and Fig. 6). Excision included tumor and surrounding tissue in adequately clear margins, down to perirectal fat (Fig. 7). The defect in the rectal wall then was irrigated with $100 \mathrm{~mL}$ of diluted povidone-iodine and closed by a continuous running suture with $3 / 0 \mathrm{ab}-$

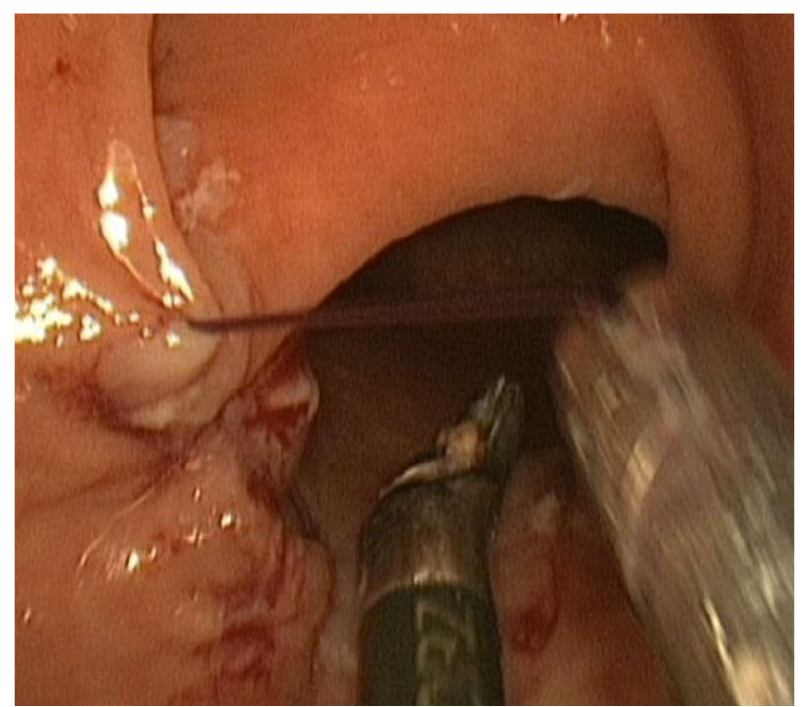

Fig. 8. Case 2. TEM, endoscopic suture of the rectal wall defect

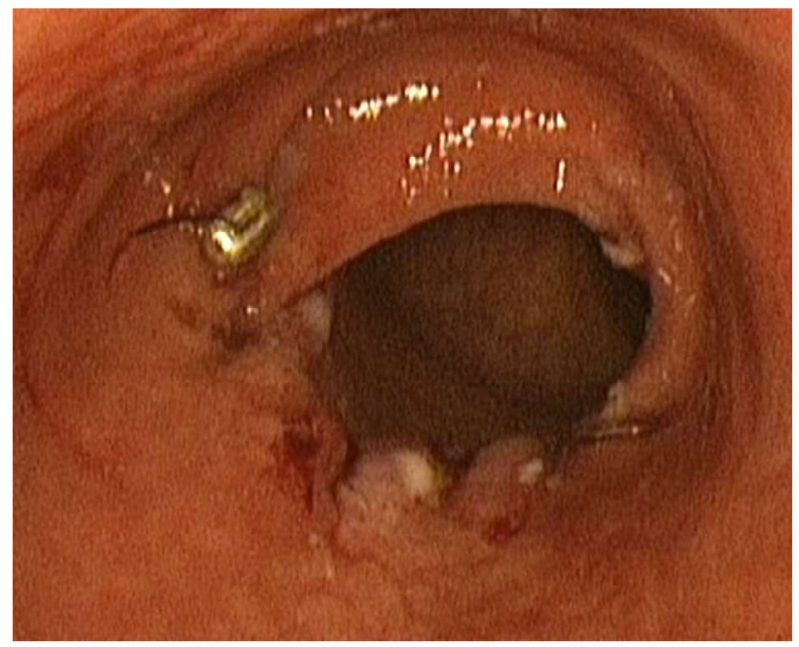

Fig. 9. Case 2. Final view after TEM full-thickness excision sorbable monofilament (Fig. 8 and Fig. 9). Postoperatively, an antibiotic was administered for three days.

The patients were followed-up by digital examinations performed at four weeks after operation, and then at every 2-3-month intervals in the first and second year, as well as by colonoscopy at 3,6 and 12 months and then annually thereafter. CT scan was used annually in patients with high-risk to look for regional and distant metastasis.

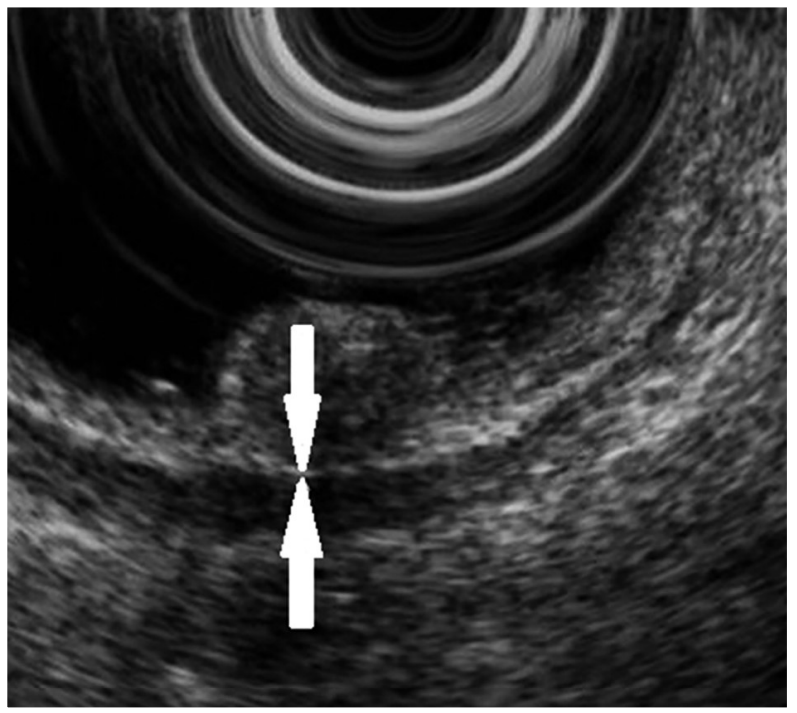

Fig. 10. EUS in Case 3. Arrows show submucosal layer, it is narrowed but not completely disrupted

\section{RESULTS}

In total, four patients with rectal carcinoid tumors were identified. Of them, two (50\%) were considered high-risk patients, who underwent TEM, full-thickness excision and other two (50\%) were considered low-risk ones, and they underwent TEM, submucosal resection.

The clinicopathologic and surgical characteristics of rectal carcinoid patients enrolled in this study were summarized in Table 2. High-risk patient's age was 54 and 69 years while low-risk patient's age was 62 and 76 years. Tumor location on rectal wall based on the Japanese Classification of Colorectal Carcinoma (28) in terms of borders of $1 \mathrm{~cm}, 6 \mathrm{~cm}$, and $12 \mathrm{~cm}$ above dentate line (DL) was the following: $\mathrm{Rb}$ (1.1-6.0 $\mathrm{cm}$ above $\mathrm{DL}), \mathrm{Ra}$ (6.1-12 $\mathrm{cm}$ above $\mathrm{DL})$, and Rs (12.1$15 \mathrm{~cm}$ above DL). In our study, tumor locations were all in rectum with majority of rectal tumors located in the middle rectum $(n=2,50 \%-R a)$, one in the low- 
Vasil Kyosev, Georgi Kotashev, Vencislav Mutafchiyski et al.

er rectum $(25 \%-\mathrm{Rb})$, and one in the upper rectum (25\% - Rs).

Tumor size was bigger in high-risk patients (14 and $20 \mathrm{~mm}$ ) than in low-risk ones (7 and $9 \mathrm{~mm}$ ), two tumors invaded the submucosal layer (Case 1 and 3 ), one - the mucosa (Case 4), and another one - the muscularis propria (Case 2) on EUS and CT examinations, none showed metastatic disease to lymph nodes, vessels and/or distal organs. Based on the preoperative endoscopic findings, all the rectal carcinoid tumors were classified as sessile type (0-Is).

The operation time was longer in the full-thickness excision group than in the submucosal resection one (45 and $55 \mathrm{~min}$ versus 27 and $33 \mathrm{~min}$ ) (Table 2). The overall rate of en bloc resection with lateral and vertical tumor-free margins was $100 \%$ (4/4) regardless of tumor size.

Histopathologic evaluation confirmed that all the tumors were classified as well-differentiated endocrine tumors (classical-type carcinoid) with architecture of trabecular or insular cell clusters with minimal cellular pleomorphism and sparse mitosis. Chromogranin A, a glycoprotein stored in secretory granules of neuroendocrine cells, was positive in $75 \%$ of the patients (Cases 1, 2, and 3). Synaptophysin, a neuron-specific enolase test, was found positive in $100 \%$ of the patients.

One patient from the high-risk group was referred to us by gastroenterologist from another hospital for complete surgery after endoscopic polypectomy with microscopically tumor positive resection margin (Case 1).

During the earlier postoperative period, one patient with full-thickness excision was complicated with acute urinary retention. He was successfully managed by consultation with urologist and conservative treatment, and no major morbidities occurred. All the patients in the study started walking on postoperative day (POD) one and peroral intake and hospital discharge was initiated on POD two.

No additional radical surgery was performed after TEM. Neither local recurrence, nor metastases to lymph nodes or distal organs was found in any of our patients during the follow-up period of mean duration of 32.7 months (range, 22-46 months). No patients died during the study period.

\section{DISCUSSION}

Rectal carcinoid tumor is a rare condition accounting for only $1.3 \%$ of the overall rectal tumor cases $(29,30)$. Tumor size is a known prognostic factor for rectal carcinoid tumors. Metastasis occurs in $5-15 \%$ of the tumors measuring 10 to $19 \mathrm{~mm}$, but this incidence increases up to $80 \%$ for tumors $20 \mathrm{~mm}$ in size or larger (31). However, tumor size, invasion depth (muscularis propria or beyond), central depression or ulceration, mitotic index, vascular invasion, and Ki-67 labeling index may predict the risk of recurrence.

Thus, rectal carcinoids that are 10 to $19 \mathrm{~mm}$ in size do not have predictable behavior, and there is no consensus in the literature concerning the appropriate therapy for tumors of this size. However, it is currently difficult to decide between treatments such as conventional polypectomy, TEM technique, and radical surgery. It appears that small rectal carcinoids $<1$ $\mathrm{cm}$ in size can be safely managed by various types of endoscopic resection techniques such as strip biopsy, endoscopic mucosa resection (EMR) with cap aspiration, and ESD. For tumors $>1$ to $\leq 2 \mathrm{~cm}$, TEM - local excision is usually recommended (32). In the current study, these two tumors ranging from 10 to $19 \mathrm{~mm}$ in size were completely resected by TEM, full-thickness excision. Radical surgery should be considered if there is evidence of invasion to the muscularis propria or lymph node metastasis. The preoperative pelvic radiological evaluations, such as CT or EUS are critical, and no enlarged lymph nodes were found in patients before surgery.

In our study, EUS was useful for measuring the size or depth of rectal carcinoid tumors, and the accuracy of the preoperative determination was 100\% (Fig. 10). For rectal carcinoid tumors, EUS was not considered difficult because the endoscope is easily maneuvered in the rectum and the tumor was visualized as a low echoic mass with clear margins. Therefore, preoperative EUS assessment can be recommended to general surgeons, colorectal surgeons, and gastrointestinal endoscopists as an excellent diagnostic tool for rectal carcinoid tumors.

Most rectal carcinoids extend into the submucosa, as shown in the current study, and conventional polypectomy can't remove the tumors completely. There is a relatively high incidence rate of tumor- 
positive resection margins or subsequent recurrences. The incidence rate of a positive margin after endoscopic polypectomy for rectal carcinoid tumors is $17 \%$, even in an institution with much experience (33). Therefore, patient's selection for endoscopic polypectomy should be carefully done, and, probably, limited to small carcinoids growing like a polyp, because endoscopic polypectomy using a two channel colonoscope often results in crush injury of resected specimens (34). Otherwise, it is advisable to perform TEM as the intervention to achieve complete removal of rectal carcinoid in selected high-risk patients.

If the resected margin is identified as tumor positive after endoscopic rectal polypectomy, TEM can be an effective option for completion surgery, as described in this paper. Indeed, our case with positive margins after endoscopic rectal polypectomy has microscopic evidence of residual tumors shown in specimens obtained by TEM.

There was neither local recurrence, nor metastasis after careful follow-up assessment of our patients following TEM as completion surgery for rectal carcinoid tumor. For such patients, a major surgical procedure such as anterior resection seems too invasive because of the high incidence rate of complications as compared with TEM.

In a follow-up period, colonoscopy would be considered every 3-5 years with an aim to rule out local recurrence and metachronous colorectal malignancy $(35,36)$. Although most local recurrences could be detected by digital examination and colonoscopy in our patients, some smaller submucosal recurrence could still be missed. In this case, EUS can play a role in identifying the small submucosal recurrence, and it is recommended as a surveillance tool for monitoring the local disease recurrence $(35,36)$. For stage II/III diseases, CT surveillance would be essential to look for any distant metastases, particularly liver metastases, as we have been offering to our patients. As distant metastases may occur years after the initial treatment, long-term surveillance beyond five years was suggested in patients with high-risk factors (36).

\section{CONCLUSIONS}

Our data suggest that in appropriate patients, TEM is a safe, minimally invasive approach for local excision of rectal carcinoid tumors and, generally, leads to good oncological and surgical outcomes.
Furthermore, for patients with microscopic positive margins after endoscopic polypectomy, TEM can be an effective surgical option for complete residual tumor removal and allows precise histologic assessment of the resected specimen.

With the TEM technique, not only horizontal but also vertical margins of rectal carcinoid tumors can be visualized directly during the procedures. This procedure can provide adequate thickness of submucosa and other parts of rectal wall, and undamaged resected specimens can be obtained.

The present study has several notable limitations. First, the number of patients is too small to offer conclusive results. In addition, the follow-up period is limited. There may be a case with late relapse, however, the biological behavior of this tumor remains unclear. However, given the lack of evidence concerning TEM-local resection in high-risk rectal carcinoid patients, the results of this study may be useful to motivate future research and prompt selection of less invasive treatments.

\section{REFERENCES}

1. Scherübl H. Rectal carcinoids are on the rise: early detection by screening endoscopy. Endoscopy. 2009;41(2):162-5. doi: 10.1055/s-0028-1119456.

2. Taghavi S, Jayarajan SN, Powers BD, Davey A, Willis AI. Examining rectal carcinoids in the era of screening colonoscopy: a surveillance, epidemiology, and end results analysis. Dis Colon Rectum. 2013;56(8):952-9. doi: 10.1097/ DCR.0b013e318291f512.

3. Wang AY, Ahmad NA. Rectal carcinoids. Curr Opin Gastroenterol. 2006;22(5):529-35. doi: 10.1097/01.mog.0000239868.27328.1d.

4. Kumar AS, Sidani SM, Kolli K, Stahl TJ, Ayscue JM, Fitzgerald JF, et al. Transanal endoscopic microsurgery for rectal carcinoids: the largest reported United States experience. Colorectal Dis. 2012;14(5):562-6. doi: 10.1111/j.1463-1318.2011.02726.x.

5. Hamada $Y$, Tanaka K, Tano $S$, Katsurahara M, Kosaka R, Noda T, et al. Usefulness of endoscopic submucosal dissection for the treatment of rectal carcinoid tumors. Eur J Gastroenterol Hepatol. 2012;24(7):770-4. doi: 10.1097/ MEG.0b013e3283526f38.

6. Niimi K, Goto O, Fujishiro M, Kodashima S, Ono S, Mochizuki S, et al. Endoscop- 
Vasil Kyosev, Georgi Kotashev, Vencislav Mutafchiyski et al.

ic mucosal resection with a ligation device or endoscopic submucosal dissection for rectal carcinoid tumors: an analysis of 24 consecutive cases. Dig Endosc. 2012;24(6):443-7. doi: 10.1111/j.1443-1661.2012.01303.x.

7. Konishi T, Watanabe T, Kishimoto J, Kotake K, Muto T, Nagawa H., Japanese Society for Cancer of the Colon and Rectum. Prognosis and risk factors of metastasis in colorectal carcinoids: results of a nationwide registry over 15 years. Gut. 2007;56(6):863-8. doi: 10.1136/gut.2006.109157.

8. Mani S, Modlin IM, Ballantyne G, Ahlman H, West B. Carcinoids of the rectum. J Am Coll Surg. 1994;179(2):231-48.

9. Sauven P, Ridge JA, Quan SH, Sigurdson ER. Anorectal carcinoid tumors. Is aggressive surgery warranted? Ann Surg. 1990;211(1):67-71.

10. Higaki S, Nishiaki M, Mitani N, Yanai H, Tada M, Okita K. Effectiveness of local endoscopic resection of rectal carcinoid tumors. Endoscopy. 1997;29(3):171-5.

11. Naunheim KS, Zeitels J, Kaplan EL, Sugimoto J, Shen KL, Lee CH, et al. Rectal carcinoid tumors treatment and prognosis. Surgery. 1983;94(4):670-6.

12. Ramage JK, Goretzki PE, Manfredi R, Komminoth P, Ferone D, Hyrdel R, et al.; Frascati Consensus Conference participants. Consensus guidelines for the management of patients with digestive neuroendocrine tumours: well-differentiated colon and rectum tumour/carcinoma. Neuroendocrinology. 2008;87(1):31-9.

13. Onozato Y, Kakizaki S, Iizuka H, Sohara N, Mori M, Itoh H. Endoscopic treatment of rectal carcinoid tumors. Dis Colon Rectum. 2010;53(2):169-76.

14. Scherübl H, Jensen RT, Cadiot G, Stölzel U, Klöppel G. Management of early gastrointestinal neuroendocrine neoplasms. World J Gastrointest Endosc. 2011;3(7):133-9. doi: 10.4253/wjge.v3.i7.133.

15. Park CH, Cheon JH, Kim JO, Shin JE, Jang BI, Shin SJ, et al. Criteria for decision making after endoscopic resection of well-differentiated rectal carcinoids with regard to potential lymphatic spread. Endoscopy. 2011;43(9):790-5. doi: 10.1055/s-0030-1256414.

16. Saito Y, Otake Y, Sakamoto T, Nakajima T, Yamada M, Haruyama S, et al. Indications for and technical aspects of colorectal endoscopic submucosal dissection. Gut Liver. 2013;7(3):263-9. doi: 10.5009/ gnl.2013.7.3.263.
17. Zhong DD, Shao LM, Cai JT. Endoscopic mucosal resection vs endoscopic submucosal dissection for rectal carcinoid tumours: a systematic review and meta-analysis. Colorectal Dis. 15(3):283-91. doi: 10.1111/codi.12069.

18. Moon SH, Hwang JH, Sohn DK, Park JW, Hong CW, Han KS, et al. Endoscopic submucosal dissection for rectal neuroendocrine (carcinoid) tumors. J Laparoendosc Adv Surg Tech A. 2011;21(8):695-9. doi: 10.1089/lap.2011.0068.

19. Park HW, Byeon JS, Park YS, Yang DH, Yoon SM, Kim KJ, et al. Endoscopic submucosal dissection for treatment of rectal carcinoid tumors. Gastrointest Endosc. 2010;72(1):143-9. doi: 10.1016/j. gie.2010.01.040.

20. Zhou PH, Yao LQ, Xu MD, Chen WF, Zhong YS, Gao WD, et al. Endoscopic submucosal dissection for rectal carcinoid tumors. Zhonghua Wei Chang Wai Ke Za Zhi. 2007;10(4):319-22 (in Chinese).

21. Zhou PH, Yao LQ, Qin XY, Xu MD, Zhong YS, Chen WF, et al. Advantages of endoscopic submucosal dissection with needle-knife over endoscopic mucosal resection for small rectal carcinoid tumors: a retrospective study. Surg Endosc. 2010;24(10):2607-12. doi: 10.1007/ s00464-010-1016-z.

22. Onozato Y, Kakizaki S, Ishihara H, Iizuka H, Sohara N, Okamura S, et al. Endoscopic submucosal dissection for rectal tumors. Endoscopy. 2007;39(5):423-7. doi: 10.1055/s-2007-966237.

23. Buess G, Hutterer J, Theiss M, Moebel W, Isselhard W, Pichlmaier H. Das System für die transanale endoskopische Rektumoperation. Chirurg 1984;55(10):677-80.

24. Buess G, Kipfmüller K, Ibald R, Heintz A, Hack $\mathrm{D}$, Braunstein $\mathrm{S}$, et al. Clinical results of transanal endoscopic microsurgery. Surg Endosc. 1988;2(4):245-50.

25. Heintz A, Mörschel M, Junginger T. Comparison of results after transanal endoscopic microsurgery and radical resection for T1 carcinoma of the rectum. Surg Endosc. 1998;12(9):1145-8.

26. Middleton PF, Sutherland LM, Maddern GJ. Transanal endoscopic microsurgery: a systematic review. Dis Colon Rectum. 2005;4(2):270-84.

27. Winde G, Nottberg H, Keller R, Schmid KW, Bünte H. Surgical cure for early rectal carcinoma (T1): transanal endoscopic microsurgery vs. anterior resection. Dis Colon Rectum. 1996;39(9):969-76. 
28. Japanese Research Society for Cancer of the Colon and Rectum. General rules for clinical and pathological studies on cancer of the colon, rectum, and anus: Part I. Clinical classification. Jpn J Surg. 1983;13(6):557-73.

29. Godwin JD 2nd. Carcinoid tumors. An analysis of 2,837 cases. Cancer. 1975;36(2):560-9.

30. Teleky B, Herbst F, Langle F, Neuhold N, Niederle B. The prognosis of rectal carcinoid tumours. Int $J$ Colorectal Dis. 1992;7(1):11-4.

31. Jetmore AB, Ray JE, Gathright JB Jr, McMullen KM, Hicks TC, Timmcke AE, et al. Rectal carcinoids: the most frequent carcinoid tumor. Dis Colon Rectum. 1992;35(8):717-25.

32. Kinoshita T, Kanehira E, Omura K, Tomori T, Yamada H. Transanal endoscopic microsurgery in the treatment of rectal carcinoid tumor. Surg Endosc. 2007;21(6):970-4. doi: 10.1007/s00464-006-9155-y.

33. Kobayashi K, Katsumata T, Yoshizawa S, Sada M, Igarashi M, Saigenji K, et al. Indications of endoscopic polypectomy for rectal carcinoid tumors and clinical usefulness of endoscopic ultrasonography. Dis Colon Rectum. 2005;48(2):285-91. doi: 10.1007/ s10350-004-0765-y.

34. Iishi $\mathrm{H}$, Tastuta $\mathrm{M}$, Yano $\mathrm{H}$, Narahara $\mathrm{H}$, Iseki K, Ishiguro S. More effective endoscopic resection with a two-channel colonoscope for carcinoid tumors of rectum. Dis Colon Rectum. 1996;39(12):1438-9.

35. Holinga J, Khalid A, Fasanella K, Sanders M, Davison J, McGrath K. Metastatic risk of diminutive rectal carcinoid tumors: a need for surveillance rectal ultrasound? Gastrointest Endosc. 2012;75(4):913-6. doi: 10.1016/j.gie.2011.11.032.

36. Anthony LB, Strosberg JR, Klimstra DS, Maples WJ, O’Dorisio TM, Warner RR, et al.; North American Neuroendocrine Tumor Society (NANETS). The NANETS consensus guidelines for the diagnosis and management of gastrointestinal neuroendocrine tumors (nets): well-differentiated nets of the distal colon and rectum. Pancreas. 2010;39(6):76774. doi: 10.1097/MPA.0b013e3181ec1261. 